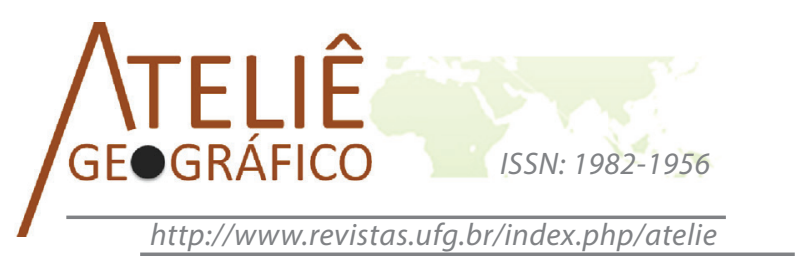

\title{
O uso seletivo do território na distribuição dos serviços de saúde: um estudo de Sobral-Ceará
}

\author{
Selective use of the territory in the distribution of health \\ services: a study of Sobral-Ceará
}

\section{El uso selectivo del territorio en la distribución de los servicios de salud: un análisis de Sobral - Ceará}

\author{
Maria Cássia de Sá \\ Universidade Estadual Vale do Acaraú - UVA \\ cassia.conrado@hotmail.com \\ Virgínia Célia Cavalcante de Holanda \\ Universidade Estadual Vale do Acaraú - UVA \\ Universidade Estadual do Ceará - UECE \\ virginiaholand@hotmail.com
}

\begin{abstract}
Resumo
Na perspectiva de captar as expressões que Sobral congrega na rede urbana cearense, nos debruçamos durante essa pesquisa no estudo do uso do território de Sobral pelos serviços de saúde. Enquanto cidade média, a referida cidade responde por uma das quatro macrorregiões de saúde no estado, reunindo estabelecimentos públicos e privados que oferecem assistência à saúde nos três níveis de complexidade que compõe a rede de ações e serviços de saúde no Brasil. Os serviços de saúde seguem a lógica de uso corporativo do território, e Sobral historicamente vem garantindo seu lugar nessa topologia.
\end{abstract}

Palavras-chave: Cidade Média. Sobral. Serviços de Saúde. Uso do Território.

\begin{abstract}
In the perspective of capturing the expressions that Sobral aggregates in the Ceará's urban network, we worked during this research in the study of the use of territory of Sobral by health services While average city, this city accounts for one of the four macro health regions in the state, bringing together public and private health care offers three levels of complexity that makes up the network of actions and healthcare
\end{abstract}


services in Brazil. Health services, follow the logic of corporate use of the territory, and Sobral historically has guaranteed its place in this topology.

Keywords: Medium City. Sobral. Health Services. Use of the territory.

\section{Resumen}

En la perspectiva de captar las expresiones que Sobral aduna en la rede urbana cearense, direccionamos esa investigación en el estudio del uso del territorio de Sobral por los servicios de salud. Mientras ciudad media, la referida ciudad revelase como una de las cuatro macro-regiones de salud en estado, reuniendo establecimientos públicos y privados que ofrecen asistencia a la salud en los tres niveles de complexidad que compone la rede de acciones y servicios de salud en Brasil. Los servicios de salud siguen a lógica de uso corporativo del territorio, y Sobral históricamente viene garantizando su sitio en esa topología.

Palabras Clave: Ciudad Media. Sobral. Servicios de salud. Uso del territorio.

\section{Introdução}

O município de Sobral, situado no Noroeste do Estado do Ceará a $235 \mathrm{~km}$ de Fortaleza (Figura 1), nas últimas duas décadas vem crescentemente assumindo novos papéis no contexto econômico cearense se constituindo em um núcleo urbano de forte expressão.

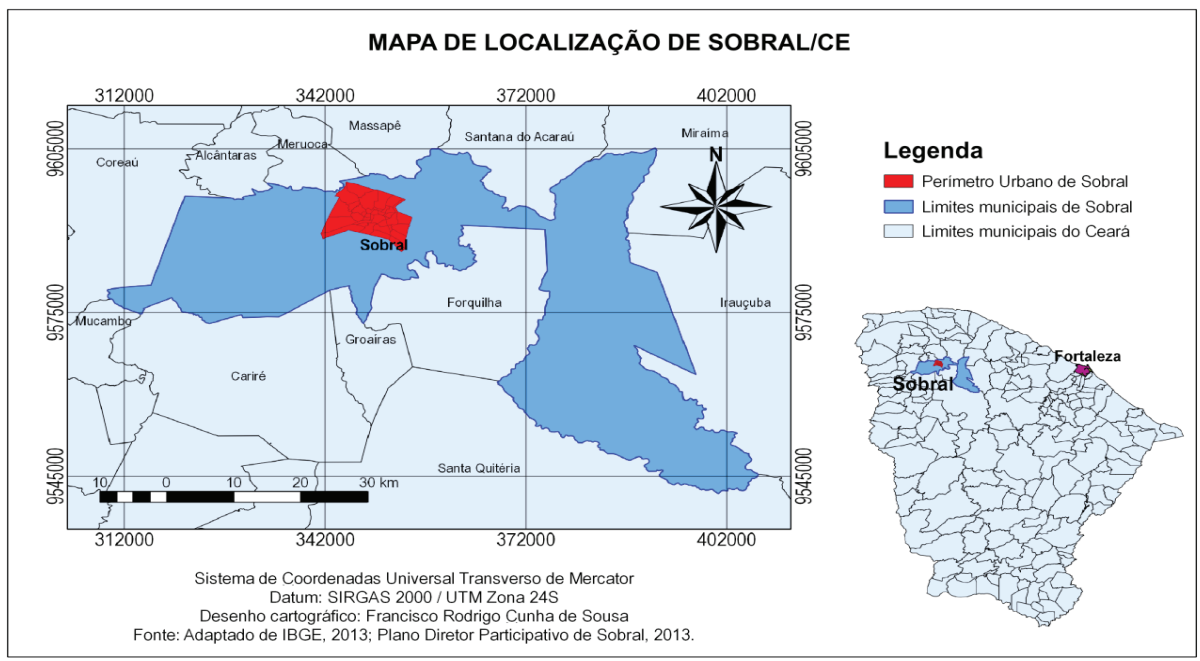

Figura 1. Localização do Município de Sobral - Ceará

Essa expressividade é determinante durante o processo de implantação do Sistema Único de Saúde - SUS ${ }^{1}$ e a partir da Municipalização do Sistema de Saúde

1. A política de saúde pública brasileira se estrutura a partir da Lei ${ }^{\circ} 8.080$, conhecida como Lei Orgânica de Saúde ou Lei do Sistema Único de Saúde - SUS. 
de Sobral em 1997 tem-se a constituição de uma rede física com capacidade de ofertar serviços de saúde para o município e sua macrorregião, fazendo de Sobral uma referência no Estado do Ceará, competindo ao município, a partir de então, garantir além do atendimento da sua população, a cobertura aos demais municípios que não possuem densidade técnico-informacional para abrigar estabelecimentos de saúde voltados aos casos de média e alta complexidade.

Muito embora a concepção de território adotada nas políticas de saúde esteja associada à territorialidade, devendo os territórios de saúde, a serem delimitados, considerar espaços com identidades em comum, situações epidemiológicas semelhantes, dentre outras características, a territorialidade não constitui nosso foco de análise. Nos voltamos ao estudo dos serviços de Saúde na perspectiva que estes assumem enquanto setor da economia que, não alheio às condições dada pelos lugares, é pensado, normatizado e estruturado de acordo com as lógicas de mercado, produzindo territórios, definindo usos, dinâmicas, fluxos, etc., sendo, portanto, nesta perspectiva que se direciona nossa abordagem. Tendo como objetivo central a análise do uso do território de Sobral pelo serviço de saúde e seus significados na conformação do papel regional no presente.

Para atingir o objetivo proposto, buscamos dialogar com teóricos que discutem o processo de urbanização, a constituição das redes, principalmente das redes urbanas, e as convergências destas a partir dos usos do território. Neste processo, nos debruçamos sobre os trabalhos de pesquisadores dos quais destacamos Santos (2006, 2009), Santos \& Silveira (2001), Dias (2004), Corrêa (1994 e 2006) e Contel (2010).

A apreensão das dinâmicas dos serviços de saúde se constituiu um desafio maior, uma vez que poucos trabalhos discutem a territorialização destes serviços na perspectiva geográfica, destacamos aqui os trabalhos de Almeida (2005 e 2013) e Ferraz (2009), sendo também significativos os trabalhos de estudiosos que discutem a gestão da saúde como, Andrade (2000, 2004) e Arruda, Martins e Souza (2010). Contudo, foi a pesquisa documental que nos ofereceu alguns aportes primordiais para o entendimento do funcionamento dos sistemas de saúde e os apontamentos sobre como estes se territorializam no espaço.

A pesquisa documental consistiu no levantamento e seleção de documentos oficiais, leis, relatórios, legislações, planos de governo, programas e projetos relacionados à temática estudada. Nessa perspectiva, obtivemos informações nas seguintes fontes: Ministério da Saúde, Secretaria de Saúde do Estado do Ceará - SESA, e Secretaria da Saúde e Ação Social de Sobral.

\section{Políticas de regulamentação da saúde e as seletividades espaciais}

Discorrendo sobre a generalização do processo de urbanização Santos (2009, p. 138) aborda que "estaríamos, agora, deixando a fase da mera urbanização da sociedade, para entrar em outra, na qual defrontamos a urbanização do território" diante do já mencionado período técnico-científico-informacional que vem conduzindo a produção 
de processos socioespaciais, como a metropolização, assinalada pela presença da metrópole em todos os lugares; a desmetropolização, a partir do expressivo crescimento de outros centros urbanos como as cidades médias, também chamadas por Santos (2008) como cidades intermediárias ${ }^{2}$; e a involução metropolitana, em que se observa maior crescimentos das cidade médias que dos centros metropolitanos.

Dessa forma, a organização do espaço em rede repercute com esses processos imperiosamente na dinâmica urbana das cidades médias, uma vez que essas vivenciam atualmente uma forte ampliação de suas dinâmicas socioeconômicas e passam a abrigar em seu território, cada dia mais, grandes e distintos empreendimentos econômicos de produção material e não material. O que traz uma transformação nas relações estabelecidas com outros centros urbanos, se constituindo um grande campo de estudos acerca das relações, sobreposições e articulações que vão constituir o território em rede.

Silveira (2011, p. 05) coloca que às formas presentes em dado território têm papel fundamental na "produção de maiores densidades técnicas, informacionais e normativas", contudo, tão importante quanto à forma se instituem "às ações humanas, isto é, o comportamento no território das pessoas, das instituições, das empresas, determinando um dinamismo que varia segundo sua origem, sua força, sua intencionalidade, seus conflitos". Assim, a difusão de novos sistemas de engenharia para as cidades médias reflete na dinâmica das formas e na feição que o território destas assume. O que impulsiona novos usos, assumindo, enquanto espaço luminoso ${ }^{3}$ no território, um papel importante na divisão territorial do trabalho, como um ponto de convergência das redes, dotadas de uma densidade técnica onde as possibilidades de uso do território são maiores.

Os serviços de saúde se caracterizam como uma atividade que desde os primórdios possibilitam a identificação dos lugares centrais em uma dada rede urbana, principalmente pela raridade que alguns serviços possuem de acordo com o nível de complexidade. $\mathrm{Na}$ atualidade, a prestação de serviços de saúde assume expressiva dinâmica econômica, e a mesma raridade conduz a instalação destes serviços em espaços luminosos, passíveis de ampliação e reprodução do capital investido no setor.

Walter Christaller e Michel Rochefort (Contel, 2010), ao discutirem acerca dos elementos que nos possibilita traçar uma definição dos "lugares centrais", apontam os serviços de saúde, mais especificamente, como um dos elementos que auxiliariam na definição de um lugar central, dentro da lógica de territorialização em locais que

2. Santos (2008) trabalha o conceito de 'cidade intermediária', considerando que as cidades de 'tamanho médio' se estabeleceriam apenas como ponto de contato das redes produtivas e comerciais, abrigando, por exemplo, filiais de grandes empresas sem ter o poder de comando sobre os circuitos econômicos.

3. Os espaços luminosos são territórios que, a partir de uma modernização seletiva, congregam maiores densidades técnicas e informacionais, despontando como pontos de atração para os mais diversos investimentos. Por oposição, os espaços inseridos onde há uma rarefação de técnica e informação, são considerados espaços opacos, possuindo menor condição de abrigar e atrair fluxos de capitais. 
possibilitasse um consumo mínimo desse serviço, dado a raridade do consumo a partir da oferta especializada.

Atualmente, podemos ainda nos voltar ao estudo da oferta dos serviços de saúde, ampliando a ótica de análise ao uso seletivo no território, uma vez que, os atores voltados à oferta deste condicionam, tendo principalmente na figura do estado, $\mathrm{o}$ desenvolvimento de todo um planejamento territorial da rede de oferta, bem como, dos pontos de acesso.

O Artigo 198 da Constituição Federal de 1988 define que "as ações e serviços públicos de saúde integram uma rede regionalizada e hierarquizada e constituem um sistema único". Considerando a complexidade de todo o processo de descentralização das ações e serviços de saúde, o Ministério da Saúde abre mão das Normas Operacionais de Assistência à Saúde - NOAS, com o objetivo de disciplinar o processo e definir as estratégias que fundamentam a operacionalidade do SUS, através da hierarquização dos serviços de saúde. Atualmente, a lógica de pactuação entre as esferas de gestão do SUS, federal, estadual e municipal, normatiza as responsabilidades que estes assumem junto ao sistema.

Dentre as diretrizes que regem a Lei do SUS, apontamos três delas que assumiram caráter essencial, e prioritário, na estruturação do SUS: a descentralização do sistema, através da municipalização, em que os municípios passam a atuar enquanto gestores da saúde no nível de atenção a que lhe compete; a hierarquização, que compreende a divisão dos serviços em três níveis de atenção: primário, secundário e terciário; e, a partir dessa, a regionalização, que dividi os territórios em Regiões de Saúde.

\section{O papel das cidades médias na formação das Regiões de Saúde}

A hierarquização e a regionalização do SUS se dão a partir da complexidade exigida em cada nível de atenção. Almeida (2005, p. 560) apresenta em seus estudos uma breve classificação dos equipamentos da saúde de acordo com o nível de complexidade, formando a seguinte tipologia:

Nível primário: oferecem, no geral, serviços externos, ambulatoriais, nas áreas de promoção da saúde e prevenção e detecção de doenças, funcionando essencialmente com base em quatro áreas fundamentais da atividade médica: pediatria, ginecologia, clínica médica e medicina social.

Nível secundário - concentra-se as maternidades, os prontos-socorros (estabelecimento com atendimento contínuo para as situações de urgência e emergência médica e/ou odontológica, tendo aqueles com leitos destinados à observação e /ou à acomodação daqueles que aguardam remoção hospitalar), os hospitais distritais, além das policlínicas (que apresentam atendimento ambulatorial especializado), clínicas, casas de saúde ou centros médicos, em que se contempla um atendimento ambulatorial e de internação, clínico, cirúrgico, restrito, ou não, a uma especialidade (por exemplo, uma clínica de doenças respiratórias ou em centro de urgências pediátricas). 


\begin{abstract}
Nível terciário - concentra os hospitais, estabelecimentos voltados essencialmente para a assistência médica em regime de internação, geralmente em áreas urbanas, funcionando dia e noite. Possuem distintos graus de incorporação tecnológica, dispondo de médico e pessoal de enfermagem em regime permanente. Podem ser classificados segundo o porte (pequeno, médio ou grande) e o grau de incorporação tecnológica (pequeno, moderado e grande), sendo que alguns deles são voltados exclusivamente para o atendimento mais especializado.
\end{abstract}

A Atenção Primária à Saúde, também conhecia como Atenção Básica, abarca os estabelecimentos de nível primário. Não requerendo grande incorporação tecnológica, encontram-se dispersamente no território, sendo obrigatoriamente ofertada em todos os municípios. A atenção primária compreende o atendimento e as ações voltadas à promoção da saúde, prevenção de doenças, educação em saúde, etc..

A Atenção Secundária à Saúde, é desenvolvida em centros urbanos que possua condições de abrigar em seu território os equipamentos de nível secundário, anteriormente especificados, atuando enquanto microrregião assistencial de saúde para municípios circunvizinhos. Os principais critérios utilizados pelo Estado na formação destas microrregiões, diz respeito à contiguidade territorial entre os municípios; a existência de um sistema viário de comunicação entre eles, que possa ser base de uma circulação intermunicipal e apresente uma demanda espontânea por serviços de saúde, assim como, de acordo com os apontamentos de Arruda, Martins e Souza (2010, p. 40), a "existência de hospitais com no máximo quatro clínicas básicas, quais sejam, Pediátrica, Clinica médica e Gineco-Obstetrícia e Cirurgia Geral; e disposição política dos municípios para pactuação".

A estratégia de Atenção Terciária à Saúde congrega os serviços ambulatoriais e hospitalares que prestam atendimento especializado e de alta complexidade. A raridade do serviço conduz uma distribuição centralizada no território, em que alguns centros urbanos atuam como polos macrorregionais de assistência terciária à saúde.

Deste modo, é com base nessa hierarquização dos serviços que se estabelece a regionalização do SUS. A NOAS (01/2001) concebe a regionalização como, "uma lógica de planejamento integrado, compreendendo as noções de territorialidade na identificação de prioridades de intervenção e de conformação de sistemas funcionais de saúde [...]", essa mesma norma classifica uma região de saúde "considerando as características demográficas, socioeconômicas, geográficas, sanitárias, epidemiológicas, oferta de serviços, relações entre municípios, entre outras", de cada estado (BRASIL, 2006, p. 110).

Entretanto, a lógica de regionalização presente na normatização do SUS, ao sair do papel e se constituir ação nas esferas de administração pública, abre mão da flexibilidade presente nos escritos da norma e assume caráter somente de unidade de intervenção estatal, em que a contiguidade na formação de territórios assume papel mais importante que a vivência que o sujeito traça no espaço. 
Nessa conjuntura, além das metrópoles, as cidades médias despontam como território possuidor de propriedades imprescindíveis à instalação dos serviços de saúde mais especializados e de alta complexidade, assim como de quaisquer atividades econômico-produtivas, surgindo perante a intensificação do processo de urbanização, como espaço luminoso dotado de sistemas de engenharia modernos que garantem a fluidez necessária, constituindo um importante ponto nodal, com forte força aglomerativa ao desempenhar o papel de centro de oferta de bens e serviços à região que polariza. Desse modo, as cidades médias se estabelecem como território profícuo aos serviços de saúde que demandam uma frequência menor de consumo, principalmente os serviços mais especializados, que são ofertados apenas em pontos do território que possibilitam condições mínimas de consumo.

Se voltarmos aqui aos estudos de Walter Christaller e Michel Rochefort (apud CONTEL, 2010), a que já fizemos referência, quando estes ainda no início do séc. XX apontavam o estudo da oferta dos serviços médicos mais especializados como uma das variáveis que auxiliaria na definição da centralidade de uma dada cidade, observa-se que a lógica é semelhante na política de descentralização e regionalização do SUS, principalmente na definição das macrorregiões, uma vez que o município sede deve apresentar a mesma centralidade na rede urbana regional, fornecendo as "condições mínimas" de funcionamento do sistema: a base material e o dado social.

A definição das Regiões de Saúde se dá a partir do grau de incorporação tecnológica exigida pelo nível de atenção, assim, a distribuição dos serviços de saúde no território segue a racionalidade capitalista de acumulação. Os centros urbanos habilitados para a oferta da Atenção terciária à Saúde, por exemplo, são aqueles espaços luminosos que contemplados com ciência, técnica e informação, estão inseridos na lógica de divisão territorial do trabalho, o que assinala a distribuição desigual e seletiva dos serviços mais especializados e, por conseguinte, demonstram a direção dos maiores investimentos do setor.

A Saúde embora se constitua um direito social assegurado constitucionalmente, não se submete apenas à lógica das políticas públicas do Estado, mais também, imperiosamente, pelas lógicas do mercado, ao estabelecer o território como norma, aonde, pelos usos que abriga, se habilita ou não, o desenvolvimento de determinada atividade. Santos (1999) coloca que essa "mediação jurídica" e a "mediação técnica" atuam de modo complementar, uma vez que "o espaço, por seu conteúdo técnico, é regulador, mas um regulador regulado, já que as normas administrativas (além das normas internas às empresas) é que em última análise, determinam os comportamentos" (SANTOS 1999, p. 183-184).

Neste sentido, o dado social e material do território é que vai definir os investimentos públicos e da iniciativa privada, despontando os centros urbanos, que se constituem nó da rede urbana, o ambiente propício à instalação dos serviços de saúde. As especialidades médicas de maior complexidade, sejam elas ofertadas por estabelecimentos públicos, privados, filantrópicos, etc., ainda vão se encontrar predominantemente nos centros com densidade técnica que possibilite o funcionamento dos serviços mais 
modernos, assim como a lucratividade no caso das empresas que atuam na prestação de serviços de assistência à saúde.

Anormatização do território pelo estado não está presente somente na implantação de sistemas técnicos no território, mas também na legislação civil, financeira e fiscal, a exemplo dos incentivos fiscais, que Antas Jr. (2005, p. 53) coloca como "normatização do espaço geográfico pelas ações". O referido geógrafo aponta também, que partir de uma concepção do estado como;

Detentor de toda regulação social, econômica e política produz analises lógicas mas não proficientes. O território no ocidente é regulado pelo estado, pelas corporações e pelas instituições civis não estatais, sobretudo aquelas de alcance planetário. (ANTAS JUNIOR, 2005, p. 19)

Desse modo, as cidades médias se firmam enquanto economia de aglomeração devido a uma regulação que é fruto da parceria público/privado, e as dinâmicas inerentes a territorialização dos serviços de saúde caracterizam bem essa dinâmica, uma vez que os processos que conduzem à urbanização do território possibilitam que as cidades médias assumam um papel importante nas atuais políticas de saúde dentro da lógica da regionalização e hierarquização da rede de serviços.

\section{A composição da rede de ações e serviços de saúde em Sobral}

A reestruturação urbana caracterizada pelo processo de urbanização do território, embora se materialize no Ceará ainda timidamente, vem difundindo para além da região metropolitana novos sistemas de engenharia, em que as cidades médias vivenciam com impulsionamento em sua vida de relações, tanto no recorte horizontal, quanto no recorte vertical. Essas dinâmicas que assumem no território contribuem na efetivação das cidades médias cearenses, enquanto centros possuidores de forte economia de aglomeração.

Deste modo, a rede de ações e serviços de saúde estruturada durante a implantação do SUS no Ceará, teve início com a formação de 03 Macrorregiões de Saúde, Macrorregião de Fortaleza, tendo como sede a capital do estado, a Macrorregião de Sobral e a Macrorregião do Cariri, as duas últimas implantadas com sede nas cidades médias de Sobral e Juazeiro do Norte. Em 2011 teve início uma reestruturação do processo de regionalização que estabeleceu a divisão da Macrorregião de Fortaleza, que cobria 101 municípios, implantando a Macrorregião do Sertão Central com sede em Quixadá, responsável agora por 20 municípios.

Atualmente as Regiões de Saúde no Ceará formam uma rede que se estrutura em 04 macrorregiões e 22 microrregiões assistenciais: a Macrorregião de Fortaleza, que atende a 57,71\% da população do estado; a Macrorregião de Sobral, atendendo 18,45\% da população; a Macrorregião do Cariri cuja cidade-polo é Juazeiro do Norte, responsável pelo atendimento de $16,52 \%$ da população; e a recém normatizada, Macrorregião do Sertão Central com sede em Quixadá, responsável por 7,32\% da população do estado do Ceará (Figura 2). 


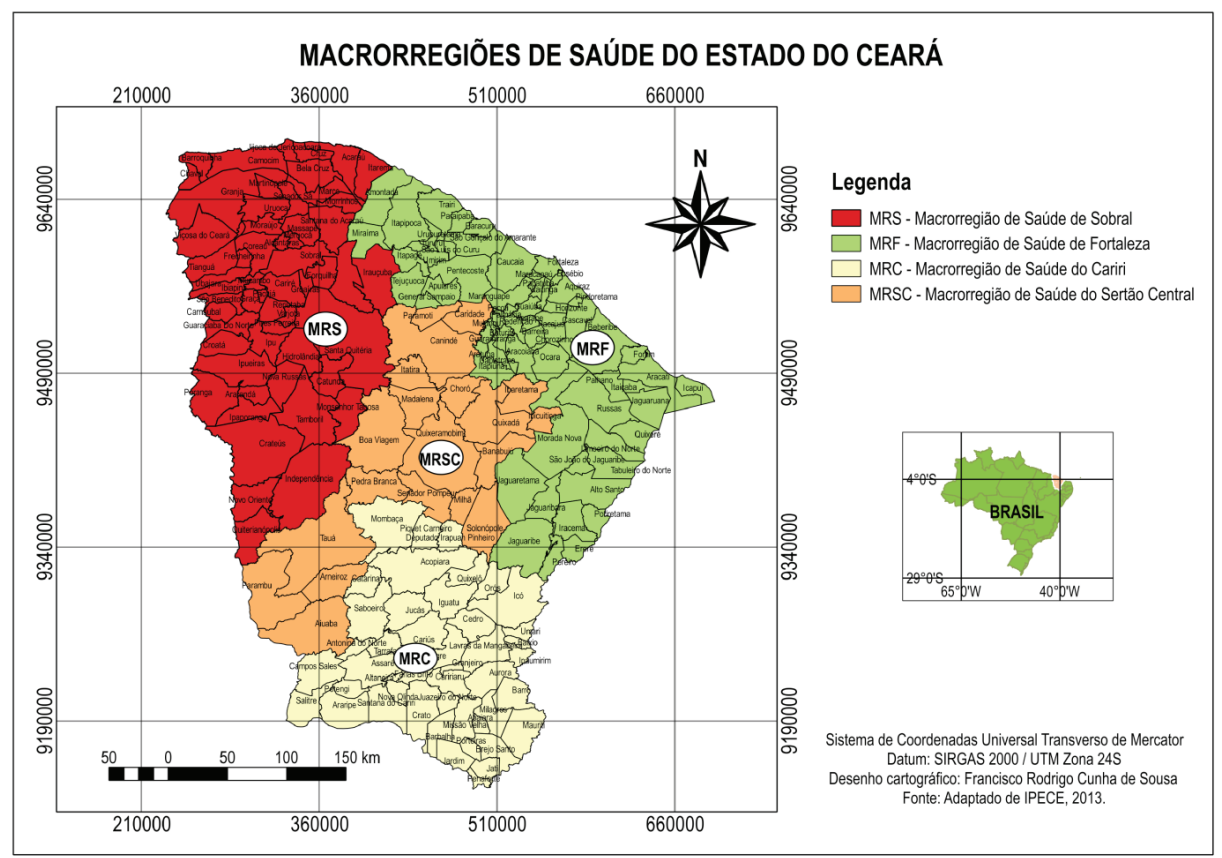

Figura 2. Divisão das Macrorregiões de Saúde do Estado do Ceará

Esta hierarquização dos serviços que constitui a formação das Regiões de Saúde, é também uma estratégia de racionalizar os gastos e otimizar os recursos, ao elencar como municípios-polos aqueles que, com maiores densidades técnica e informacionais são detentores de uma economia de escala que os evidencie na rede urbana.

Nem todos os municípios congregam as condições necessárias para fornecer todos os serviços de saúde, dada às condições sociais, características demográficas, dentre outras. Centram-se então, na sede da macrorregião, as ações de maior complexidade que devem ser tratadas em nível estadual ou federal, principalmente quando consideramos o alto custo financeiro de alguns serviços mais raros. Assim, a hierarquização do sistema vai de encontro ao uso de um território dotado, por um conjunto de economias externas ${ }^{4}$, que sejam atrativas aos agentes privados vinculados a prestação destes serviços mais especializados e raros.

A Macrorregião de Sobral abrange, além da sua própria Região de Saúde, mais quatro, as microrregiões de Acaraú, Tianguá, Crateús e Camocim, abarcando além do seu território mais 54 municípios (Figura 3).

4. O par de conceitos "economias externas" e "deseconomias externas" vêm da discussão acerca das economias de escala como vantagens de aglomeração e especialização em alguns pontos do território, desenvolvido pelo economista Alfred Marshall (1982) (CONTEL, 2010), a primeira diz respeito a características que atuam como atrativas de atividades econômicas, ao passo que a segunda atua como dispersantes destas no território. 


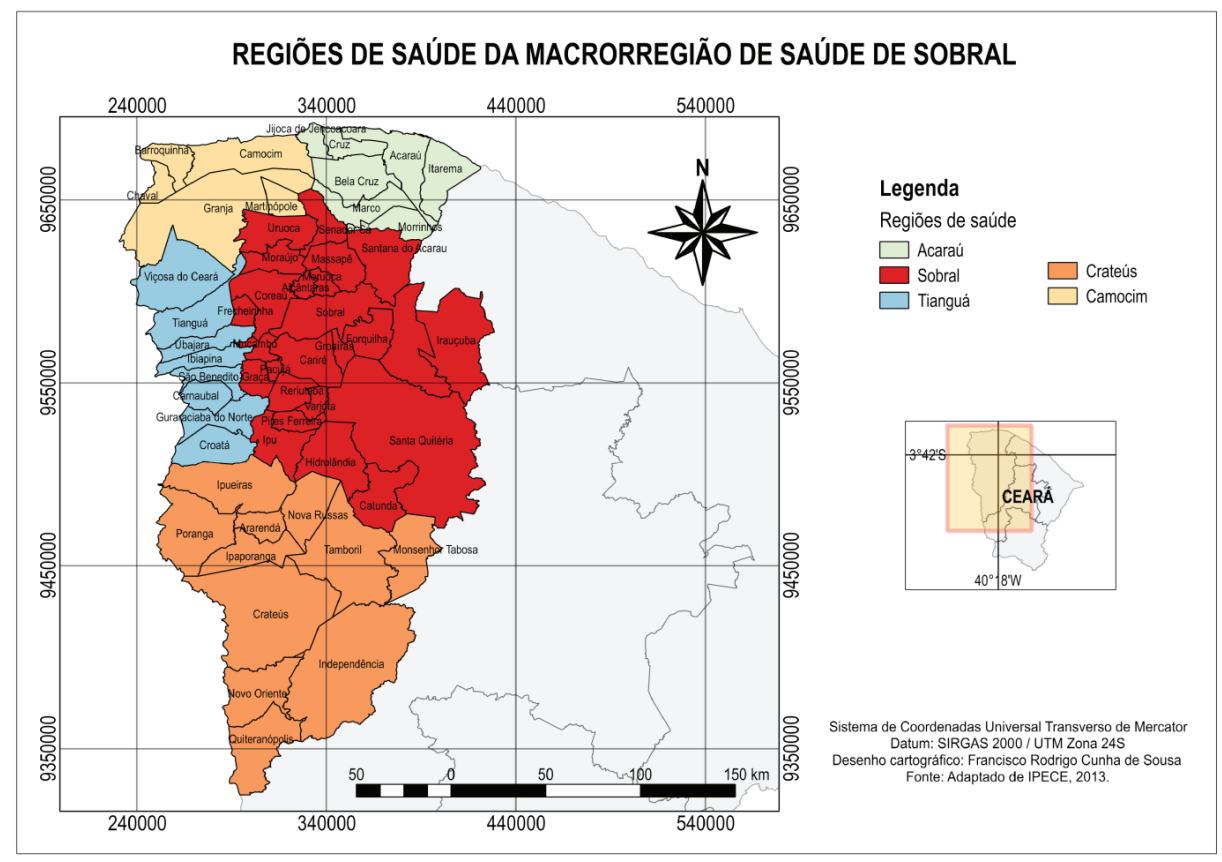

Figura 3. Macrorregião de Saúde de Sobral

A Macrorregião de Sobral tem ao todo 1.133 unidades de saúde, sendo destas unidades, $71,13 \%$ públicas, e $28,87 \%$ unidades privadas. $6,97 \%$ das unidades privadas, são unidades complementares que atendem pacientes pelo SUS (Quadro 1) (SESA-CE 2012).

Quadro 1. Distribuição das unidades de Saúde que compõem a Macrorregião de Sobral por Microrregiões de Saúde

\begin{tabular}{|l|c|c|c|c|c|}
\hline Microrregiões & Pública & $\begin{array}{c}\text { Privada Conveniada } \\
\text { ao SUS }\end{array}$ & $\begin{array}{c}\text { Privada Não } \\
\text { Conveniada ao SUS }\end{array}$ & $\begin{array}{c}\text { Privada } \\
\text { Total }\end{array}$ & Total \\
\hline Sobral & 303 & 36 & 120 & 156 & 459 \\
\hline Acaraú & 113 & 06 & 11 & 17 & 130 \\
\hline Tianguá & 175 & 16 & 64 & 80 & 255 \\
\hline Crateús & 143 & 10 & 46 & 56 & 199 \\
\hline Camocim & 72 & 11 & 07 & 18 & 90 \\
\hline Total & $\mathbf{8 0 6}$ & $\mathbf{7 9}$ & $\mathbf{2 4 8}$ & $\mathbf{3 2 7}$ & $\mathbf{1 1 3 3}$ \\
\hline
\end{tabular}

Fonte: Secretaria de Saúde do Estado do Ceará/ Plano Estadual de Saúde: 2012-2015 (2012).

Organização: SÁ, M. C. 
A institucionalização de uma Macrorregião de Saúde demonstra as estratégias de gestão e ordenamento do território pelo estado, com grande influência na constituição da rede de atendimento que se estrutura o serviço de saúde. O estado através da máquina administrativa, ou da regulação do território, direciona os fluxos e determina os "nós" das redes de atendimento, essa normatização, contudo, segue um uso corporativo do território, em que a difusão dos níveis de atenção à saúde vai ao encontro ao dinamismo econômico dos lugares.

Almeida (2008, p. 515) coloca que o entendimento do alcance desses serviços está diretamente relacionado ao entendimento da organização e uso do território,

Podemos dizer que o SUS é uma verticalidade institucional que tem um marco normativo e político-institucional no seu poder de ação. Essa verticalidade tem sido responsável pela organização dos sistemas de objetos e ações vinculados à saúde nos distintos lugares do território. Daí advém um conjunto de normas, as normas operacionais básicas que orientam os usos e os processos de descentralização dos serviços de saúde, isto é, a transferência de uma autoridade, de um poder decisório, de um financiamento e gestão de nível nacional para os níveis municipais. As verticalidades institucionais originaram horizontalidades na medida em que os lugares se adaptam as exigências normativas para participarem do SUS (ALMEIDA, 2008, p. 515).

No caso de Sobral, o processo de municipalização da gestão do Sistema de Saúde faz parte do processo de descentralização que Almeida (2008) coloca. Esse processo tem início em 1997 com base nos instrumentos legais recomendados pela Norma Operacional Básica de 1996 (NOB - 1996), que possibilitava sua inserção na Gestão Plena do Sistema Municipal (GPSM) ${ }^{5}$, nesse caso, o município com recursos do Ministério da Saúde, tem autonomia para organizar os três níveis de atenção em saúde ${ }^{6}$ : primário, secundário e terciário.

A habilitação de Sobral na GPSM reafirma sua expressividade regionalmente. O papel de centralidade na rede urbana cearense posiciona Sobral historicamente como um espaço luminoso, o quê o possibilita assumir, no processo de descentralização e hierarquização da saúde, o papel de município sede de uma macrorregião. Nesse caso, Sobral apresenta uma rede física com capacidade de fornecer assistência de alta complexidade, considerando que, a oferta desses serviços caracteriza-se pela necessidade de sistemas de engenharia que comporte a implantação de equipamentos com alta densidade tecnológica e alto custo, assim, o município se destaca como um centro urbano que possui um conjunto de economias externas que possibilita o funcionamento de um Sistema de Saúde completo. Como Santos (1999, p. 52) coloca, "de um lado os sistemas de objetos condicionam como são as ações e, de outro lado, sistemas de ações leva a criação de objetos novos ou se realiza sobre objetos preexistentes".

5. Embora o processo de habilitação na GPSM tenha início em 1997, a regularização da habilitação se dá pela NOAS/2002.

6. Os pequenos municípios que, não apresentam condições técnicas de implantar um sistema de saúde completo, são habilitados enquanto Gestor Pleno da Atenção Básica de Saúde, com autonomia para gerenciar apenas ao nível de Atenção Primária. 
De acordo com o Cadastro Nacional de Estabelecimentos de Saúde - CNES (DATASUS, 2014), os estabelecimentos que prestam serviços e desenvolvem ações em saúde totalizaram 218 até fevereiro de 2014, formando a rede de Saúde de Sobral. Dos 218 estabelecimentos, 67 são públicos, ou seja, 30,7\%, sendo 09 administrados pelo Estado e 58 pelo município; os demais 151 subdividem-se em, 64,3\% estabelecimentos privados, $1,5 \%$ filantrópico e apenas $01(0,5 \%)$ está vinculado ao sindicato.

É importante destacar também que das 218 unidades, apenas 94 são estabelecimentos credenciados que prestam atendimento pelo SUS, ou seja, 43,1\% dos estabelecimentos. Dessas 94 unidades que compõem a rede de atendimento pelo SUS em Sobral, 27 são unidades privadas contratadas que atuam em caráter complementar, o quê corresponde a $28,7 \%$ dos estabelecimentos.

A normatização do sistema estabelece que todos os 55 municípios da Macrorregião devem, obrigatoriamente, ofertar os serviços de Atenção Primária; os procedimentos de média complexidade que compõem a Atenção Secundária deverão ser pactuados entre os municípios que compõem as microrregiões, nesse caso são cinco microrregiões (Figura 03); os procedimentos não realizados na microrregião, geralmente os de alta complexidade, são pactuados pelos municípios diretamente para Sobral, que atua enquanto cidade polo de sua microrregião e da macrorregião de saúde, ofertando portanto, além da atenção básica, os procedimentos de média e alta complexidade.

O Plano Estadual de Saúde - 2012/2015 (SESA-CE, 2012), ao apresentar os dados de atendimento ambulatorial e internações, mostra um aumento significativo da abrangência que o Sistema Municipal de Saúde de Sobral possui no Estado, para além dos 55 municípios que compõem a Macrorregião de Saúde, Sobral registrou atendimentos ambulatoriais referenciados de 119 municípios, enquanto às internações referenciadas são de 85 municípios (Quadro 2). O número de municípios atendidos só é inferior ao de Fortaleza, que também é sede de uma Macrorregião de Saúde.

Quadro 2. Fluxos de acesso e assistencial à população local e referenciada - Região de Sobral / 2008 a 2011.

\begin{tabular}{|c|c|c|c|}
\hline \multicolumn{3}{|c|}{ INTERNAÇÕES OCORRIDAS } \\
\hline $\mathbf{A n o}$ & Pop. Local & Pop. Referenciada & \% Pop. Referenciada \\
\hline $\mathbf{2 0 0 8}$ & 38.427 & 8.246 & 17,67 \\
\hline $\mathbf{2 0 0 9}$ & 37.793 & 7.779 & 17,07 \\
\hline $\mathbf{2 0 1 0}$ & 35.847 & 7.239 & 16,80 \\
\hline $\mathbf{2 0 1 1}$ & 33.307 & 7.015 & 17,40 \\
\hline & ATENDIMENTOS AMBULATORIAIS OCORRIDOS \\
\hline $\mathbf{2 0 0 8}$ & 955.817 & 125.772 & 11,63 \\
\hline $\mathbf{2 0 0 9}$ & 1.298 .870 & 175.243 & 11,89 \\
\hline $\mathbf{2 0 1 0}$ & 1.691 .123 & 210.273 & 11,06 \\
\hline $\mathbf{2 0 1 1}$ & 2.171 .008 & 228.854 & 9,54 \\
\hline
\end{tabular}

Fonte: Secretária de Saúde do Estado do Ceará / Plano Estadual de Saúde - 2012/2015 (2012).

Organização: SÁ, M. C. 
Dentro da lógica de pactuação, todos os municípios que pertencem a Macrorregião de Saúde enviam recursos para custear os atendimentos programados. Os procedimentos realizados em Sobral, para pacientes que não pertencem a um município da Macrorregião de Saúde, como os exemplificados no quadro 02, são realizados somente em casos de urgência e emergência, sendo posteriormente ressarcidos pelo Estado. Nesse sentido, a territorialização dos serviços de saúde voltados ao atendimento pelo SUS, se dá em prol da garantia de recursos que cubra os custos dos procedimentos, nesse caso, a determinação do domicílio do paciente/usuário do sistema é importante para a captação de recursos.

Deste modo, se estabelece uma tabela unificada de procedimentos realizados na Macrorregião, através de uma Programação Pactuada Integrada - PPI, os municípios programam com as cidades-polo de micro e macrorregião de saúde, os serviços ofertados e o fluxo de atendimento mensal a ser realizado para cada procedimento. Ferraz (2009, p. 203) aborda que esse processo de pactuação é carregado de disputas de poder, uma vez que, "por ser considerado um balcão de negócios, envolve questões econômicas de repasse de verbas e interesses político-partidários que influenciam a conformação dos fluxos pactuados e o desenho da rede predefinida". Os municípios habilitados apenas para a gestão da Atenção Básica em seus territórios recebem financiamento para a compra dos procedimentos referentes aos outros níveis de atenção na micro ou na macrorregião de saúde.

Esta desigualdade no uso do território pela saúde, que segue a lógica capitalista de territorialização em espaços luminosos, na premissa de realizar um uso mais racional e estratégico do território, acaba sendo também o ponto de falência do SUS. O direcionamento de um grande número de pessoas à sede da macrorregião de saúde, onde há a concentração de serviços e equipamentos, contribui para sobrecarregar o sistema, que não possui profissionais e equipamentos suficientes para cobrir a demanda.

A constituição das regiões de saúde contribuiu para uma desigualdade regional expressa nas longas filas de espera, principalmente quando falamos dos serviços mais complexos. A lógica de uso adotada com a regionalização e hierarquização do sistema, em que o território é considerado como recurso, impulsiona o setor privado, sendo este quem mais lucra na configuração de um território usado segundo os preceitos do mercado. Segundo Dias (2004) nessa forma de organização,

Os nós das redes são os lugares das conexões, lugares de poder e de referencia, como sugere Raffestin. E antes de tudo pela conexidade que a rede solidariza os elementos. Mas ao mesmo tempo em que tem o potencial de solidarizar, de conectar, também tem de excluir. Os organismos de gestão da rede, quer se trate da gestão técnica, econômica ou jurídica não são neutros, eles colocam em jogo relações sociais entre os elementos digamos, solidarizados, e aqueles que permanecem marginalizados. Em outras palavras, nunca lidamos com uma rede máxima, definida pela totalidade de relações mais diretas, mas com a rede resultante da manifestação das coações técnicas, econômicas, políticas e sociais. (DIAS, 1994, p. 04) 
A densidade territorial presente em Sobral foi normativa para a implementação da Macrorregião, e esta também reverbera na "normatização do espaço pelas ações", como coloca Antas Jr. (2005, p. 53), quando então passamos a ter a instituição legal de uma fronteira de atendimento no SUS.

Imbricada a essa rede de assistência à saúde pelo SUS, está a rede voltada ao uso do serviço na iniciativa privada, através do Sistema de Saúde Suplementar e o Sistema Desembolso Direto. Há também uma complementariedade, entre a rede pública e a privada. A rede pública investe na rede privada através da contratação de serviços desta, enquanto a rede privada faz uso do território, que através da normatização do Estado assume o papel de comando de uma macrorregião e que, portanto, possui uma densidade técnica necessária a sua fixação, atuação e acumulação de capital. O estado aqui atua como promotor de uma infraestrutura que beneficia, sobretudo, o setor privado.

Um exemplo direto desse investimento se expressa na contratação de serviços de 27 unidades privadas, que atuam na prestação de serviços de média complexidade e, principalmente, de alta complexidade, para onde se destina a maior parte dos recursos do Fundo Municipal de Saúde de Sobral.

A especialização do território tende a ser crescente, uma vez que o território usado atua enquanto chamariz, cria-se uma base de funcionamento do sistema de saúde que busca sustentação própria. A ausência de determinado serviço de apoio ou atividade complementar, logo é percebida e encarada como potencial área de investimento, constituindo as dinâmicas de uso do território a garantia de retorno do recurso investido.

Tal agregação tem efeitos econômicos importantes. Em primeiro lugar, a acumulação de atividades semelhantes ou complementares numa área cria um efeito em massa, uma nova economia de escala que acaba por reduzir os custos globais e individuais. Em segundo lugar, a proximidade entre tais atividades produz um efeito de vizinhança que implica facilitar a difusão de informações gerais e específicas não apenas ligas aos processos, mas interessando também ao próprio funcionamento do mercado, o que representa uma vantagem comparativa. [...] Esses dois primeiros conjuntos de vantagem criam outros, relacionados a possibilidade de implantação, sustentação e desenvolvimento de serviços especializados locais. (SANTOS \& SILVEIRA, 2001, p. 300-301)

Os serviços de saúde são representativos quando falamos de concentração, centralização e "acumulação de atividades semelhantes ou complementares", como abordaram Santos \& Silveira (Idem). Essa especialização que o território Sobral assume gera uma força de atração intensa, que chama atenção de outros setores complementares ao sistema de saúde. Além das Clínicas Médicas, Hospitais, concentram-se nos mesmos bairros, e na maioria das vezes nas mesmas ruas, laboratórios, farmácias, estabelecimento de venda de materiais e artigos de apoio Médico-Hospitalar, funerárias, etc.

\section{Considerações finais}

O uso racional e estratégico do território, que também atua enquanto instância de normatização, se expressa pela definição das Regiões de Saúde com base na densidade 
técnica que os municípios abrigam, seguindo a racionalidade capitalista de acumulação, em que, tanto a iniciativa privada, quanto o sistema público de saúde utilizam o território como recurso.

Sobral historicamente desempenha funções urbanas que lhe garante destaque e dinamismo econômico, essa expressividade regional resulta em um território usado que congrega densidade técnica ao desenvolvimento de atividades econômicas mais modernas e, considerando nosso objeto de estudo, permite o funcionamento de um sistema de saúde completo, abarcando os três níveis de complexidade da atenção à saúde.

A representatividade na rede urbana cearense enquanto cidade média, é fundamental para compreendermos as atribuições que Sobral assume na rede de ações e serviços de saúde, pelo conjunto de economias externas que agrega, e pela polarização que exerce na região. Assim, apreender Sobral só é possível quando a olhamos no contexto do meio dinâmico em que se insere, aonde, para cada processo ou demanda, se estabelece uma interação com características e intensidades específicas.

A formação das regiões de saúde, muito embora seja uma alternativa que busca viabilizar o funcionamento do SUS, também produz vulnerabilidades. O território, em uma dinâmica desigual e combinada, necessita que a sustentação dos espaços luminosos seja nutrida pelos espaços opacos, fazendo esta, parte dos nexos dos movimentos solidários gerados pela unicidade do território. Contudo, em se tratando da saúde pública, essa dinâmica se caracteriza ainda mais perversa, uma vez que as desigualdades no uso do território pelos fixos de saúde que colocam, de um lado, os municípios não contemplados pelos fixos de maior complexidade tecnológica e uma população que depende de uma cidade-polo para mitigar suas necessidades de atendimento; e, do outro, os centros urbanos que apesar da concentração dos serviços e equipamentos, não conseguem abarcar as demandas de um amplo território e um grande contingente populacional, o que sobrecarrega o SUS e impulsiona o Sistema de Desembolso Direto e o Sistema de Saúde Suplementar.

O dado material e social que Sobral congrega, e que possibilita o uso do território pelos serviços de saúde, segue as racionalidades do mercado, com amplo apoio do Estado e dentro de uma estrutura socioespacial que vem se erguendo juntamente com o desenrolar do processo de urbanização. Mais do que nunca, os sujeitos valem pelo lugar em que habitam (SANTOS, 1987), e os serviços de saúde, mesmo com todos os avanços das políticas públicas que os regulamentam, seguem a lógica de uso corporativo do território, e Sobral historicamente vem garantindo seu lugar nessa topologia.

\section{Referências}

ALMEIDA, Elisa Pinto. A imobilidade relativa e seus desdobramentos no uso dos serviços públicos de Saúde. In: SOUZA, M.A. (Org.) A metrópole e o futuro: refletindo sobre Campinas. Edições Territorial: Campinas, 2008.

ALMEIDA, Eliza Pinto. O uso do território brasileiro e a segmentação dos serviços de saúde. In: X ENCONTRO DE GEÓGRAFOS DA AMÉRICA LATINA. Universidade de São Paulo: Anais. 2005. P. 552-565. 
ANTAS JR., Ricardo Mendes. Território e regulação: espaço geográfico, fonte material e não-formal de direito. São Paulo: FAPESP/Humanitas, 2005.

ARRUDA, Francisca Lúcia Nunes de; MARTINS, Fernanda Cristina Castelo de Lima; SOUZA, Maria de Fátima (Org.). Retrato do setor de saúde no Ceará. Secretária de Saúde do Estado do Ceará: Fortaleza, 2010.

BRASIL, Ministério da Saúde. Conselho Nacional de Saúde. Controle de Normas para o Controle Social no Sistema Único de Saúde - 2a Ed. - Brasília: Editora do Ministério da Saúde, 2006. 208p. (Série E. Legislação da Saúde).

CONTEL, Fábio Betioli. Rede Urbana e cidades médias no Brasil: abordagens clássicas, abordagens contemporâneas. In: HOLANDA, C. C. V.; AMORA, Z. B. (Org.) Leituras e saberes sobre o urbano: cidade do Ceará e Mossoró no Rio Grande do Norte. Sobral: Expressão Gráfica e Editora, 2010.

DIAS, Leila Cristina. Geografia e Qualidade de vida: pesando as redes técnicas. 2004.

FERRAZ, A. E. Q. O espaço em movimento: o desvelar da rede nos processos sociotécnicos do sistema de Saúde de Vitória da Conquista - Bahia. Tese (Doutorado). Núcleo de Pós-Graduação em Geografia da Universidade Federal de Sergipe, Sergipe, 2009.

SANTOS, M. A Urbanização Brasileira. 5a. Ed. São Paulo: Hucitec, 2009. 176p.

SANTOS, M. O Espaço Dividido: Os dois circuitos da economia urbana nos países subdesenvolvidos. $2^{\mathrm{a}}$ ed. $1^{\mathrm{a}}$ reimpr. São Paulo: Edusp, 2008.

SANTOS, Milton. A Natureza do espaço: técnica e tempo, razão e emoção. $3^{\mathrm{a}}$ ed. Hucitec: São Paulo, 1999.

SANTOS, Milton. O espaço do cidadão. São Paulo: Nobel, 1987.

SANTOS, Milton; SILVEIRA, Maria Laura. O Brasil: território e sociedade no início do século XXI. São Paulo: Editora Record, 2001.

SILVEIRA, Maria Laura. Território usado: dinâmicas de especialização, dinâmicas de diversidade. In: Ciência Geográfica. Ano: XV, Vol. XV,(1): Janeiro/Dezembro. Bauru, 2011. Disponível em: http://www.agbbauru.org.br/publicacoes/revista/anoXV_1/AGB dez2011_artigos_versao_internet/AGB_dez2011_01.pdf

SECRETÁRIA DE SAÚdE DO ESTADO DO CEARÁ. Plano Estadual de Saúde2012/2015. Governo do Estado do Ceará: Secretária de Saúde, 2012. Disponível em: http://www.saude.ce.gov.br/index.php/downloads/category/10-plano-estadual-desaude-2007-2010

Ministério da Saúde. Cadastro Nacional dos Estabelecimentos de Saúde do Brasil. Departamento de Informática do SUS: http://www//cnes.datasus.gov.br 


\section{Maria CÁSSIA de SÁ}

Mestre em Geografia pela Universidade Estadual do Ceará - UECE. Professora do Curso de Licenciatura em Geografia da Universidade Estadual Vale do Acaraú - UVA e Coordenadora Pedagógica da Segunda Licenciatura em Geografia PRONERA da Universidade Estadual Vale do Acaraú - UVA.

Universidade Estadual Vale do Acaraú, Centro de Ciências Humanas, Curso de Geografia. Av. John Sanford, 1845, Junco, 62030-000 - Sobral, CE - Brasil. E-mail: cassia.conrado@hotmail.com

\section{Virgínia Célia Cavalcante de Holanda}

Doutora em Geografia Humana pela Universidade de São Paulo - USP; Professora Adjunta do Curso de Graduação e do Mestrado Acadêmico em Geografia da Universidade Estadual Vale do Acaraú-UVA; Professora do Programa de Pós-Graduação em Geografia da Universidade Estadual do Ceará UECE.

Universidade Estadual Vale do Acaraú, Centro de Ciências Humanas, Curso de Geografia. Av. John Sanford, 1845, Junco, 62030-000 - Sobral, CE - Brasil. E-mail: virginia.holanda@uvanet.br

Recebido para publicação em fevereiro de 2016 Aprovado para publicação em junho de 2016 